九州大学学術情報リポジトリ

Kyushu University Institutional Repository

\title{
Bubble Coalescence on Photobioreactor Bubble Columns by Using Horizontal Baffle for Microalgae
}

Juno Dwi Putra

Department of Mechanical Engineering, Faculty of Engineering, Universitas Indonesia

Rahman, Arif

Department of Mechanical Engineering, Faculty of Engineering, Universitas Indonesia

Nining Betawati Prihantini

Department of Biology, Faculty of Mathematics and Natural Sciences, Universitas Indonesia

Deendarlianto

Department of Mechanical and Industrial Engineering, Faculty of Engineering, Universitas Gadjah Mada

他

https://doi.org/10.5109/4742133

出版情報 : Evergreen. 8 (4)，pp.861-865，2021-12. Transdisciplinary Research and Education Center for Green Technologies, Kyushu University

バージョン :

権利関係 : 


\title{
Bubble Coalescence on Photobioreactor Bubble Columns by Using Horizontal Baffle for Microalgae
}

\author{
Juno Dwi Putra ${ }^{1}$, Arif Rahman로 Nining Betawati Prihantini², Deendarlianto ${ }^{3}$, \\ Nasruddin $^{1, *}$ \\ ${ }^{1}$ Department of Mechanical Engineering, Faculty of Engineering, Universitas Indonesia, \\ Depok 16424, Indonesia \\ ${ }^{2}$ Department of Biology, Faculty of Mathematics and Natural Sciences, Universitas Indonesia, \\ Depok 16424, Indonesia \\ ${ }^{3}$ Department of Mechanical and Industrial Engineering, Faculty of Engineering, Universitas Gadjah Mada, \\ Yogyakarta, 55281, Indonesia
}

*Corresponding Author’s email: Nasruddin@eng.ui.ac.id

(Received April 30, 2021; Revised December 16, 2021; accepted December 16, 2021).

\begin{abstract}
Photobioreactors are used to increase microalgae productivity. As an improvement of the photobioreactor, the horizontal baffle is used to increase mixing capabilities. The phenomenon that occured using a horizontal baffle was bubble coalescence. A phenomenon of joining some bubble that affects mass transfer capabilities. This study aimed to reveal the effect of the horizontal baffle on the bubble size distribution and bubble behavior but only quantitatively. Bubbles distribution data was taken using a high-speed camera on three different vertical position processed by using ImageJ. Based on the result of the study, bubble coalescence occurred because of velocity difference, and the bubble was trapped, which led the bubble to coalescence. The higher position of the data retrieval shows that the more bubble with larger diameter because of the coalescence that occurs in the H/0.25, H/0.5, and below $\mathrm{h} / 0.75$. The bubble size 200-400 $\mu \mathrm{m}$ seems to be constant because of its not carried away by the wake of the larger bubble.
\end{abstract}

Keywords: Photobioreactor, Horizontal Baffle, Bubble Coalescence, Microalgae

\section{Introduction and background}

Indonesia has an extensive energy resource from fossil fuels. However, at the same time, a crisis will occur when resources run out caused by increasing energy consumption. In addition, Indonesia also has a high potential for renewable energy. Therefore, Indonesia is developing and expanding the production capacity and absorption of renewable energy to support energy independence and security programs. Aside from Indonesia, Japan is also focusing on developing renewable energy. Developing a self-sufficient energy system to produce and supply energy to support its economic development remains a strategic concern for Japan ${ }^{1)}$. Achieving energy security has become a vital challenge for Japan over time. Energy diversification, renewable energy, and energy saving technologies are significant priorities for energy security ${ }^{2}$. Renewable energy sources must be explored to sustain overall advancements and minimize energy dependency on others ${ }^{3,4)}$. Microalgae biomass can be potentially used as biofuel feedstock with an effective photobioreactor and growth mediaa,5,6,7). Microalgae are micro-organisms that grow 100 times faster and can double biomass in less than a day than land plants $^{8)}$. As biofuel feedstock, microalgae have benefits in terms of decreased land use and do not compete directly with food as with crop-based fuels ${ }^{9,10)}$.

A photobioreactor is a system for producing microorganism which needs photosynthetic for their productivity. Photobioreactor technology is can increase microalgae productivity ${ }^{9,11,2,13)}$. There are some principal factors in Photobioreactor design such as light, mixing, mass transfer, temperature, and $\mathrm{pH}$ 9,14,15,16,17). Good mixing and better mass transfer are presented in rectangular photobioreactor ${ }^{10,18)}$. The addition of static mixers or baffles aims to increase the capability of mixing. Structural optimization with horizontal baffle might enhance mass transfer and gas residence time, so thus influencing algal productivity and economically ${ }^{19,20)}$. According to Hafidho, in 2020, photobioreactors with horizontal baffles showed better simulation results in terms of microalgae growth than photobioreactors without baffles in greater gas flow rates in the form of mixing performance $^{21)}$.

In this study, using a triple segmental baffle from an adaptation of the working baffle in the heat exchanger was expected to increase mixing capabilities and microalgae 
productivity. The phenomenon that occured by using the horizontal baffle in hydrodynamics of the multiphase system was bubble coalescence. By understanding the coalescence of bubbles, the behavior and response of the system could be understood ${ }^{18,22,23)}$. Bubble coalescence is generally divided into three steps. There are bubble collision, drainage of liquid film, and film rupture. Bubble distribution should be estimated to predict the gas-liquid contact area that affects the mass transfer. The bubbles generated in the system undergo bouncing and coalescence due to contact with each other as they rise and collision. Because of the coalescence of the same diameter bubble, bubble surface area decreases $20 \%$ approximately, having a negative impact on the mass transfer ${ }^{24)}$. The indication of the bubble coalescence can be understood by investigating the increase of the Sauter mean diameter and the evolution of the bubble distribution 21,25,26,27). This study aimed to reveal the effect of the horizontal baffle on the bubble size distribution and bubble behavior but only in a quantitative manner.

\section{Method and experimental setup}

The rectangular photobioreactor with a horizontal baffle was used in this study. The total volume of the photobioreactor is $22 \mathrm{~L}$, with the height, length, and width being $400 \mathrm{~mm}$ x $400 \mathrm{~mm}$ x $150 \mathrm{~mm}$. The Photobioreactor is filled with $20 \mathrm{~L}$, giving the top clearance $30 \mathrm{~mm}$. The distance between baffle in the vertical direction is $30 \mathrm{~mm}$. Acrylic was used as the material in a photobioreactor to enable the light to enter for photosynthesis and observation. Aeration used a $0.5 \mu \mathrm{m}$ diameter sparger (SHENZEN HENGKO TECHNOLOGY) through the air filter (ADVANTEC $\AA$ ) that placed the bottom of the bubble growing region, which was controlled by the flowmeter (Viebrock) at the bottom. These experiments used tap water instead of pure algae containing water or water because it was efficient. For the minimum $1.5 \mathrm{~mm}$ bubble size, the impurities in fresh tap water can be negligible on the dynamic bubble size ${ }^{28}$ ).

The experiments were performed using two techniques, and there are video imaging to observe bubble. In the present study, the airflow rate was set at 1 LPM. A highspeed video camera, Phantom Mito M310, was used to capture the bubble phenomena. All measurements were taken at 3200 FPS with the resolution $1280 \times 800$ at the same distance in every experiment. The camera was combined with the NIKON Lens with a focal length and aperture of 85 and $2.5 \mathrm{~mm}$ to get a wide measurement plane and has a narrow depth of field ${ }^{29)}$. The technique that used in video imaging was shadowgraph or backlighted imaging. A light diffuser was used to get a homogenous illumination plane from the $50 \mathrm{~W}$ halogen lamp as the light source. The calibration of the camera found that $1 \mathrm{~mm}$ in-camera represents $10 \mu \mathrm{m}$. The image was taken in 3 different vertical distances $\mathrm{H} / 0.25, \mathrm{H} / 0.5$, and $\mathrm{H} / 0.75$.

The image split to every frame was using "MATLAB" then using “ImageJ," an open-source software application in java to process the image and analyze the bubble size measurement. The image was set into greyscale color, and then the bandpass filtering feature was used to remove the blurred image. After removing the blurred image, the image was converted into binary format to make it contrast and to reduce noise that will interfere with the accuracy ${ }^{30}$ ). To get the accurate size of the single bubble, the ratio of circularity was set $0.6-1.0$ to separate the single bubble from the overlapping bubble. The bubble size measurement use Sauter mean diameter equation that represents the average bubble size ${ }^{25,31)}$.

$$
d_{B S}=\frac{\sum n_{i} d_{i}{ }^{3}}{\Sigma n_{i} d_{i}{ }^{2}}
$$

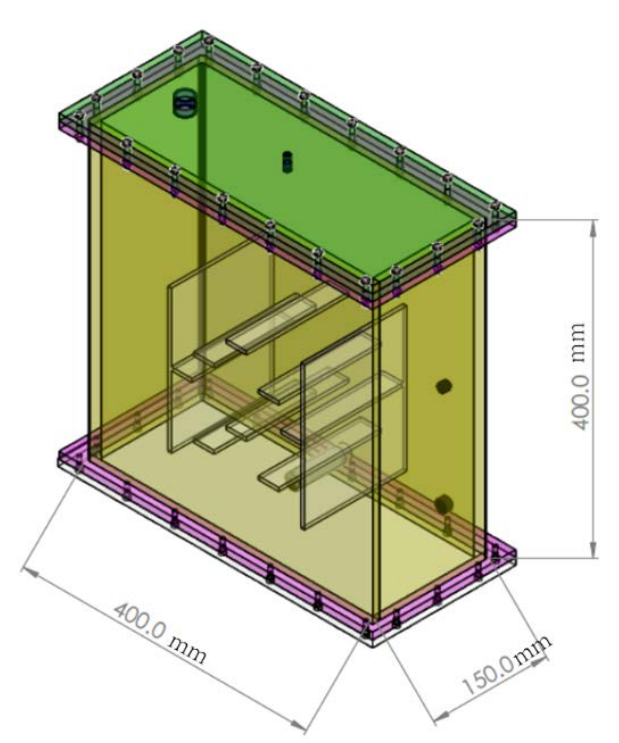

Fig. 1: Photobioreactor

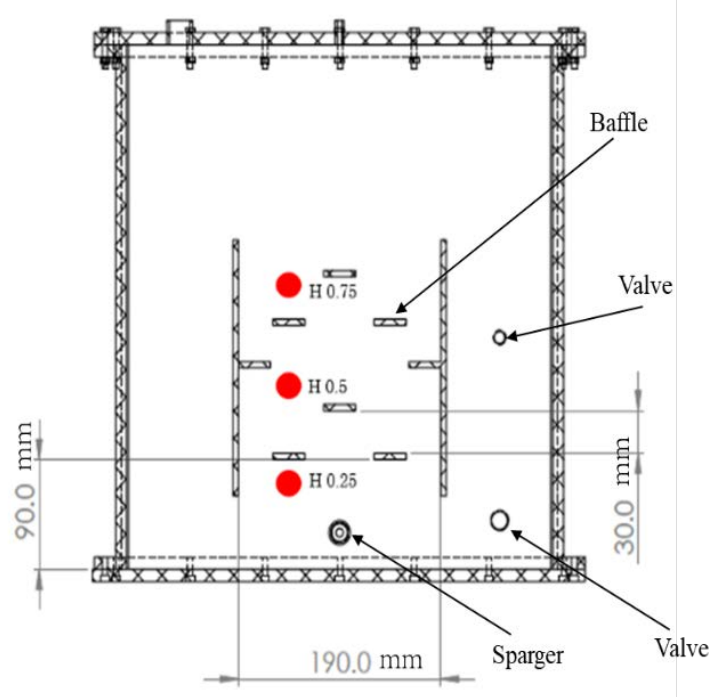

Fig. 2: Measurement Points 


\section{Results and Discussion}

The results describe the behavior of the main object. The image that has been processed shows bubble size distribution in every position. To obtain reliable data, over 2000 bubble diameters were measured. To understand the bubble density difference, the amount of bubbles has been plotted with the size of the bubble. While investigating the image from $\mathrm{H} / 0.5$, It was found that the bubbles were coalescent while rising. After the coalescence, the rise velocity decreased approximately $20 \%$, although the buoyancy force increased as the bubble growed ${ }^{26)}$. As seen in figure 3 , the bubble experience several mechanisms for bubble coalescence there are approach step, touch step, and fusion step. Figure 3 shows, because of the different rise velocities, buoyancy-driven coalescence. According to Sanada, in 2009, the bubble B bouncing with its rear bubble caused a decrease in the rising rate. Still, an increase in the horizontal speed after a collision led to bubble coalescence to bubble ${ }^{24)}$. This incidence was expected due to the bubble being generated with the sparger that has a little distance in the orifice and the shape of the sparger that leads to joining each bubble.

As shown in Fig 4, we investigate the downside of the baffle. We observe that the bubble was a collision with the baffle. The collision of the bubble makes the bubble trap because of the drag coefficient. While the bubble rises, velocity decrease, the approach velocity of the bubble increase ${ }^{24)}$. The increasing of the local gas hold up, and the coalescence probability was produced because the bubble was trapped, this led the bubble to be coalesced.

As seen in Fig 4, five bubbles coalesce, beginning with the tiny ones and then growing large. Those phenomena not only occur in the H/0.25 but also $\mathrm{H} / 0.75$, so in the lead to produce a larger bubble, the first contact of the bubble was leading the coalescence as the starting point in bubble coalescence time.

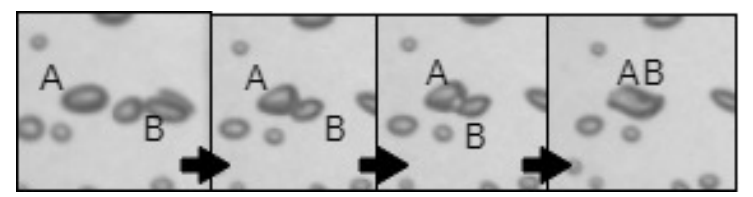

Fig 3: Bubble Coalescence in H/0.5 after baffle

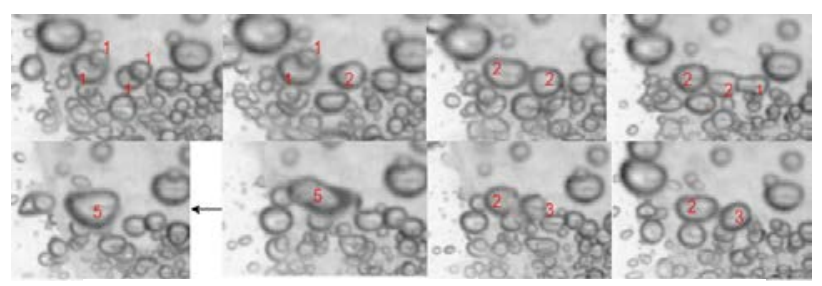

Fig 4: Bubble Coalescence in H/0.25 below baffle

The result from the bubble distribution in threeposition was obtained, as shown in Fig. 5. The more the number of bubbles, the smaller the bubbles produced by the double loop fluid oscillator. The smaller the bubble size, the greater the concentration of carbon dioxide contained in the air. A high concentration of carbon dioxide is a desirable condition for the photosynthetic process of microalgae.

Based on the data, the distribution of the bubbles was homogenous in the H/0.25 with the higher value of 100 $300 \mu \mathrm{m}$ of the bubble size. After the first baffle, the effect of the coalescence phenomena occured, the bubble size 100-300 $\mu \mathrm{m}$ was dropped while the bubble size 600-1000 $\mu \mathrm{m}$ increase as an effect of the bubble coalescence below the baffle. The phenomenon was continued in the freerising zone and at the second baffle. The result showed that the bubble distribution in $\mathrm{H} / 0.75$ was different due to its wonders. The size of the bubble seems to increase, that shown in the graphic. The Effect of the coalesces is proven by finding the value of Sauter mean diameter in Table 1 . That increase is parallel with Fig 5. However, some of the coalescence bubbles grew about $>20 \mathrm{~mm}$, as shown in Fig. 6. Those phenomena effect of trapped bubble in some baffle. Because of the coalescence of the bubble, the capabilities of the mass transfer seem to decrease.

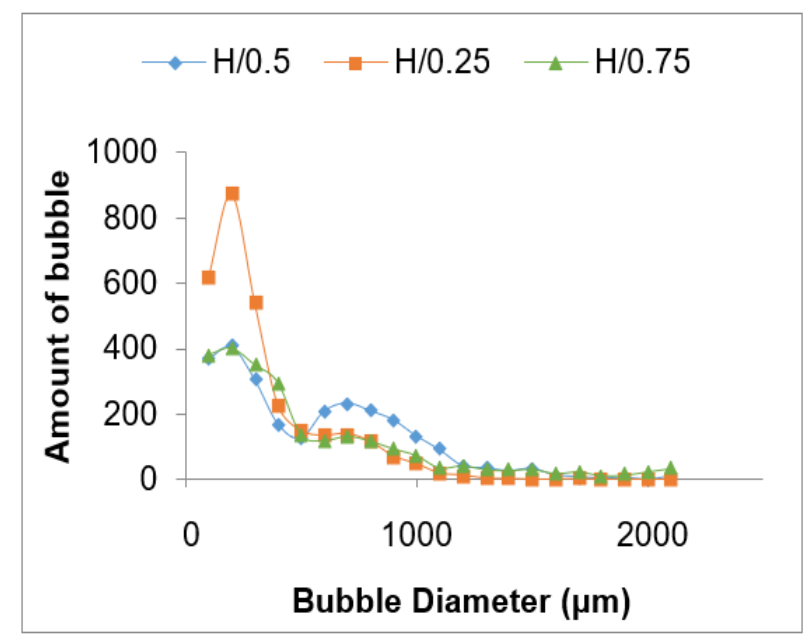

Fig 5: Bubble Distribution Graphic

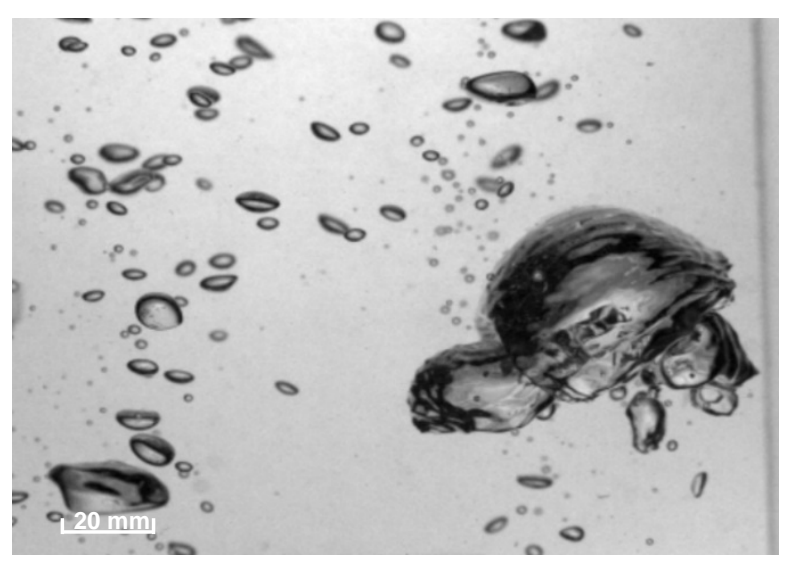

Fig 6: Bubble size $>20 \mathrm{~mm}$ 
Table 1 Sauter mean diameter

\begin{tabular}{c|c}
\hline Position & $\begin{array}{c}\text { Sauter Mean } \\
\text { Diameter }(\boldsymbol{\mu m})\end{array}$ \\
\hline $\mathrm{H} / 0.25$ & 675 \\
\hline $\mathrm{H} / 0.5$ & 1001 \\
\hline $\mathrm{H} / 0.75$ & 1125 \\
\hline
\end{tabular}

\section{Conclusions}

In this study, bubble distribution and bubble coalescence phenomena as an effect using horizontal baffle were evaluated. The higher the data retrieval location, the more bubble with a bigger diameter due to the coalescence that occurs in the $\mathrm{H} / 0.25, \mathrm{H} / 0.5$, and below $\mathrm{H} / 0.75$. The bubble size of $200-400 \mu \mathrm{m}$ appears to remain constant since it is not carried away by the wake of the larger bubble. The bubble coalescence below the baffle because of its trapped effect of the drag coefficient and tend to coalesce as an effect increasing the local gas hold up. Otherwise, the mixing capabilities of the photobioreactor were increased due to its baffle and the bubble flow.

\section{Acknowledgements}

The author would like to thank Research and Development Directorates Universitas Indonesia for funding this research through the Hibah Publikasi Terindeks International (PUTI) Doktor to Nasruddin [grant number NKB-702/UN2.RST/HKP.05.00/2020].

\section{Nomenclature}

$d_{i} \quad$ Bubbles diameter ( $\left.\mathrm{mm}\right)$

$d_{B S} \quad$ Sauter mean diameter (mm)

\section{References}

1) M.K. Barai, and B.B. Saha, "Energy security and sustainability in japan," Evergreen Joint Journal of Novel Carbon Resource Sciences \& Green Asia Strategy., 2 (1) 49-56 (2015).

2) H. Gima, and T. Yoshitake, "A comparative study of energy security in okinawa prefecture and the state of hawaii," Evergreen Joint Journal of Novel Carbon Resource Sciences \& Green Asia Strategy., 3 (2) 3644 (2016).

3) J. Milano, H.C. Ong, H.H. Masjuki, W.T. Chong, M.K. Lam, P.K. Loh, and V. Vellayan, "Microalgae biofuels as an alternative to fossil fuel for power generation," Renewable \& Sustainable Energy Reviews., 58 180-197 (2016).
4) J. Mohtasham, "Review article-renewable energies," Energy Procedia., 74 1289-1297 (2015).

5) M.K. Lam, K.T. Lee, and A.R. Mohamed, "Current status and challenges on microalgae-based carbon capture," International Journal of Greenhouse Gas Control., 10 456-469 (2012).

6) A. Rahman, N.B. Prihantini, and Nasruddin, "Fatty acid of microalgae as a potential feedstock for biodiesel production in indonesia," AIP Conference Proceedngs., 2062, 020059-1-020059-8 (2019).

7) A. Sanchez, F. Garcia, and A.C. Gomez, "Bubblecolumn and airlift photobioreactors for algal culture," American Institute of Chemical Engineers Journal., 46 (9) (2000).

8) M.R. Tredici., "Photobiology of microalgae mass cultures: understanding the tools for the next green revolution,” Biofuels, 1143 (2010).

9) S.A. Scott, M.P. Davey, J.S. Dennis, I. Horst, C.J. Howe, D.J. Lea-Smith, and A.G. Smith, "Biodiesel from algae: challenges and prospects," Current Opinion in Biotechnology., 21 (3) 277-286 (2010).

10) E. Stephens, I.L. Ross, J.H. Mussgnug, L.D. Wagner, M.A. Borowitzka, C. Posten, O. Kruse, and B. Hankamer, "Future prospects of microalgal biofuel production systems," Trends in Plant Science., 15 (10) 554-564 (2010).

11) L. Xu, P.J. Weathers, X.R. Xiong, and C.Z. Liu, "Microalgal bioreactors: challenges and opportunities,” Engineering in Life Sciences., 9 (3) 178-189 (2009).

12) K.K. Vasumathi, M. Premalatha, and P. Subramanian, "Parameters influencing the design of photobioreactor for the growth of microalgae," Renewable \& Sustainable Energy Reviews., 16 (7) 5443-5450 (2012).

13) A. Rahman, N.B. Prihantini, and Nasruddin, "Biomass production and synthesis of biodiesel from microalgae synechococcus hs-9 (cyanobacteria) cultivated using bubble column photobioreactors," Evergreen Joint Journal of Novel Carbon Resource Sciences \& Green Asia Strategy., 7 (4) 564-570 (2020).

14) S.R. Ardiansyah, A.M. Orlando, A. Rahman, N.B. Prihantini, and Nasruddin, "Tubular photobioreactor: a preliminary experiment using synechococcus sp. (cyanobacteria) cultivated in npk media for biomass production as biofuel feedstock," Evergreen Joint Journal of Novel Carbon Resource Sciences \& Green Asia Strategy., 6 (2) 157-161 (2019).

15) B.L. Gatamaneni, V. Orsat, and M. Lefsrud, "Factors affecting growth of various microalgal species," Environmental Engineering Science., 35 (10) 10371048 (2018).

16) F.G. Acién Fernández, J.M. Fernández Sevilla, and E. Molina Grima, "Photobioreactors for the production of microalgae," Reviews in Environmental Science and Biotechnology., 12 (2) 131-151 (2013). 
17) M.K. Lam, and K.T. Lee, "Microalgae biofuels: a critical review of issues, problems and the way forward,” Biotechnology Advances., 30 (3) 673-690 (2012).

18) P.M. Kilonzo, A. Margaritis, M.A. Bergougnou, J. Yu, and Q. Ye, "Effects of geometrical design on hydrodynamic and mass transfer characteristics of a rectangular-column airlift bioreactor,” Biochemical Engineering Journal., 34 (3) 279-288 (2007).

19) L. lin Wang, Y. Tao, and X. zhong Mao, “A novel flat plate algal bioreactor with horizontal baffles: structural optimization and cultivation performance," Bioresource Technology., 164 20-27 (2014).

20) L. Zhao, Z. Tang, Y. Gu, Y. Shan, and T. Tang, "Investigate the cross-flow flat-plate photobioreactor for high-density culture of microalgae," Asia-Pacific Journal of Chemical Engineering., 13 (5) 1-11 (2018).

21) H.I. Muhammad, A. Rahman, N.B. Prihantini, Deendarlianto, and Nasruddin, "The application of poly-dispersed flow on rectangular airlift photobioreactor mixing performance," Evergreen Joint Journal of Novel Carbon Resource Sciences \& Green Asia Strategy., 7 (4) 571-579 (2020).

22) X. Li, W. Wang, P. Zhang, J. Li, and G. Chen, "Interactions between gas-liquid mass transfer and bubble behaviours," Royal Society Open Science., 6 (5) (2019).

23) R. V. Chaudhari, and H. Hofmann, "Coalescence of gas bubbles in liquids," Reviews in Chemical Engineering., 10 (2) 131-190 (1994).

24) T. Sanada, A. Sato, M. Shirota, and M. Watanabe, "Motion and coalescence of a pair of bubbles rising side by side,” Chemical Engineering Science., 64 (11) 2659-2671 (2009).

25) S. Mohagheghian, and B.R. Elbing, "Characterization of bubble size distributions within a bubble column," Fluids., 3 (1) (2018).

26) R. Sudiyo, and B. Andersson, "Bubble trapping and coalescence at the baffles in stirred tank reactors," American Institute of Chemical Engineering - Wiley Intersci., 7 (PART 1) 405-410 (2009).

27) A. Rahman, J.D. Putra, N.B. Prihantini, T.M.I. Mahlia, M. Aziz, Deendarlianto, and N. Nasruddin, "Cultivation of synechococcus hs-9 in a novel rectangular bubble column photobioreactor with horizontal baffle," Case Study and Thermal Engineering., 27 (June) 101264 (2021).

28) P.C. Duineveld, "Bouncing and coalescence of bubble pairs rising at high reynolds number in pure water or aqueous surfactant solutions," Flow, Turbulence and Combustion., 58 (1-3) 409-439 (1997).

29) W.E. Juwana, A. Widyatama, O. Dinaryanto, W. Budhijanto, Indarto, and Deendarlianto, "Hydrodynamic characteristics of the microbubble dissolution in liquid using orifice type microbubble generator," Chemical Engineering Research and Design., 141 436-448 (2019).

30) A. Rodriguez, A. Patalano, and C.M. García, "Rectification of image velocity results ( river ): a simple and user-friendly toolbox for large scale water surface particle image velocimetry ( piv ) and particle tracking velocimetry (ptv)," Computers \& Geosciences., 109 323-330 (2017).

31) D.F. McGinnis, and J.C. Little, "Predicting diffusedbubble oxygen transfer rate using the discrete-bubble model,” Water Research., 36 (18) 4627-4635 (2002). 